\title{
Measures of taxonomic distinctness do not reliably assess anthropogenic impacts on intertidal mollusc communities
}

\author{
Trudy L. Costa ${ }^{1,2,3}$, Timothy D. O'Hara ${ }^{1, *}$, Michael J. Keough ${ }^{2}$ \\ ${ }^{1}$ Sciences Department, Museum Victoria, GPO Box 666, Melbourne, Victoria 3001, Australia \\ ${ }^{2}$ Department of Zoology, University of Melbourne, Victoria 3010, Australia \\ ${ }^{3}$ Present address: School of Biological Sciences, University of Wollongong, New South Wales 2500, Australia
}

\begin{abstract}
Indices of taxonomic distinctness measure the taxonomic breadth of a community and may be more sensitive to human impacts than conventional diversity indices. They have the advantage of being, in theory, insensitive to sampling effort and can be calculated using presence/absence data. The average taxonomic distinctness index and variation in taxonomic distinctness index were used to assess the effects of putative human impacts on molluscan community composition at 63 rocky intertidal platforms on the coast of Victoria, Australia. The use of 2 sampling techniques, viz. timed searches and quadrats, was compared. Sites exposed to sewage discharge maintained high taxonomic distinctness, and those exposed to high levels of human visitation did not have consistently lower values than controls. Results varied, sometimes markedly, depending on which survey technique was used. Neither average taxonomic distinctness nor its variance were strongly correlated with large-scale environmental gradients, small-scale habitat differences or other diversity indices. It is most likely that taxonomic distinctness measures did not discriminate sites exposed to putative disturbance because of the high taxonomic diversity of intertidal mollusc assemblages, and because low values of taxonomic distinctness were not exclusive of impacted conditions.
\end{abstract}

KEY WORDS: Trampling - Sewage · Disturbance - TAXDTEST · Community composition · Invertebrate · Diversity

\section{INTRODUCTION}

Human activities can have a range of adverse effects on the structure and functioning of rocky intertidal communities. Quantifying the effects of human impacts on biodiversity is vital for predicting changes to ecosystem function, and for the ongoing management of rocky intertidal reefs. However, the efficacy of various summary indices for this purpose remains the subject of much research and debate (Harper \& Hawksworth 1994, Warwick \& Clarke 1995, Magurran 2004, Buckland et al. 2005, Fleishman et al. 2006).

Indices of species richness are widely used to quantify or monitor the effects of anthropogenic disturbance. A decline in species richness may be concomitant with severe or chronic human-induced perturbation (Fair- weather 1990, but see Keough \& Quinn 1998), but is not always associated with more intermediate levels of disturbance. In these cases, species richness is often less sensitive-values can remain constant despite a change in the type of species present (Somerfield et al. 1997). Fluctuations in species richness can be confounded by natural environmental variation (Warwick \& Clarke 1998, Blanchard \& Bourget 1999), meaning they do not necessarily denote a decline in ecosystem 'health' or functional diversity (Hawkins et al. 1986, Keough \& Quinn 1991, Clarke 1993, Dufrene \& Legendre 1997). Another disadvantage of a number of diversity indices is that they are often affected by sampling effort (Warwick \& Clarke 1995, 1998, Rogers et al. 1999, Clarke \& Warwick 2001, Magurran 2004). This is problematic when the sampling area or volume cannot 
be completely standardised in a study (e.g. Smith \& Simpson 2002), or if different sampling procedures have been used.

Examining the taxonomic distinctness of organisms within a community may be a more useful means of assessing human impacts on biodiversity, because the replacement of species by taxonomically dissimilar ones can be detected, a change that might leave species richness unaltered, but may be functionally significant (Warwick \& Clarke 1995, 2001). Clarke \& Warwick (2001) described a set of indices that quantify the degree of relatedness of species in a sample. The average taxonomic distinctness index (AvTD, $\Delta^{+}$) measures the average taxonomic distance between species at a site, or the average path length joining every pair of individuals in a sample, using a standard Linnean classification, i.e. species, genus, family, order, class etc. (Warwick \& Clarke 1995). The variation in taxonomic distinctness index $\left(\operatorname{VarTD}, \Lambda^{+}\right)$measures the variation in the average distance between species pairs (Clarke \& Warwick 2001).

Both AvTD and VarTD are calculated using presence/absence data. They have been demonstrated to be independent of sampling effort (Clarke \& Warwick 1998, 1999, Warwick \& Clarke 1998), and can be used as standard univariate measures in analysis of variance (ANOVA) models or regression analyses. Additionally, AvTD can be examined in its broader spatial context by comparing a sample to a master list of animals from the surrounding region. This procedure (TAXDTEST), implemented using PRIMER-E software, compares the observed AvTD values in a sample to predicted values generated using species from across the study area (Clarke \& Warwick 2001, Warwick \& Clarke 2001). The master list incorporates species that are represented at sites exposed to minimal levels of disturbance, which provides a benchmark against which impacted sites can be assessed - where sites have values lower than expected, it is possible that they are suffering diversity loss and are disturbed in some way (Warwick \& Clarke 1998, Smith \& Rule 2002, Marchant 2007).

Few studies have examined the use of taxonomic distinctness measures on rocky intertidal invertebrate communities (but see Smith \& Simpson 2002), but a number of studies have used AvTD to assess effects of human disturbance on other marine assemblages. Roberts \& Connell (2008) used AvTD, along with the Shannon diversity index, to investigate the effects of nutrient enrichment and grazer removal (mimicking pollution and overharvesting) on algal communities. They found that phylogenetic diversity was sensitive to the experimental manipulation of both factors, whereas Shannon diversity was not. In the same way, Terlizzi et al. (2005) found significant differences in
AvTD values between control and impact locations for subtidal mollusc communities around a sewage outfall, but no significant difference in the mean number of species. Nevertheless, in other habitats (freshwater streams), taxonomic distinctness measures have been found unsuitable for detecting disturbance. They can be correlated with environmental gradients, which conceal the effects of human-induced disturbances (Bhat \& Magurran 2006, Heino et al. 2007), or correlated with species richness and other diversity indices, making them redundant as biodiversity measures (Somerfield et al. 1997, Hall \& Greenstreet 1998, Hewitt et al. 2005). Moreover, indices of taxonomic distinctness may have low sensitivity to the effects of disturbance when the taxonomic range or resolution of the assemblage under study is limited (Marchant 2007).

The aim of this study was to examine the suitability of taxonomic distinctness for detecting human impacts on intertidal molluscan communities on rocky shores. Molluscs are the largest taxonomic group available for study in these habitats and have been shown to be a useful surrogate for broader patterns of biodiversity (Gladstone 2002, Smith 2005, 2008). Taxonomic distinctness was examined at 63 rocky intertidal platforms in Victoria, Australia, by grouping the platforms into those relatively undisturbed, those subjected to high levels of human visitation and those adjoining sewage discharges. The following questions were addressed: (1) Can taxonomic distinctness measures (AvTD and VarTD) be used to discriminate impacted sites along the coast? (2) How do the responses of AvTD and VarTD compare to those of other diversity indices? (3) Is AvTD correlated with other diversity indices? (4) Is AvTD correlated with environmental gradients?

The cost of environmental monitoring programmes is always an important constraint, particularly when individual sampling units are time-consuming to sample. Because AvTD and VarTD are based on presence/ absence data, we hypothesised that a more streamlined sampling procedure might give the same result at lower cost. We therefore examined the use of 2 different techniques-quadrats and timed searches. Timed searches may be more efficient, as they have been shown to encounter more species in a given amount of time (Benkendorff \& Davis 2002).

\section{MATERIALS AND METHODS}

Study sites. Surveys were conducted at 63 intertidal rock platforms in western and central Victoria (Fig. 1). These sites covered $\sim 570 \mathrm{~km}$ along a predominantly east-west coastline in southeastern Australia. Sites in eastern Victoria were not included, as this is a distinct 


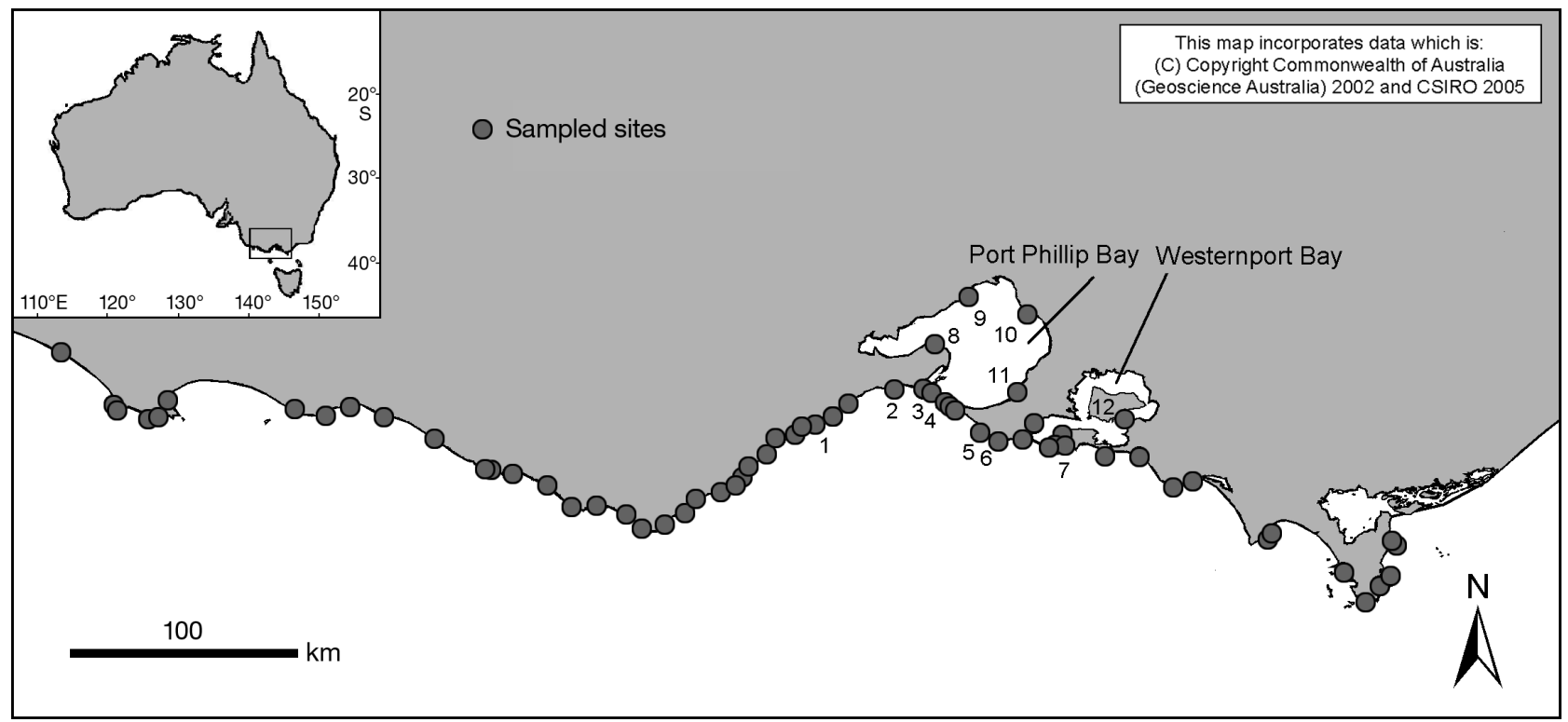

Fig. 1. Coast of Victoria, Australia, and the sites included in the study. 1: Point Grey, 2: Barwon Heads, 3: Point Lonsdale, 4: Sorrento, 5: Boags Rocks, 6: Boags Rocks East, 7: Pyramid Rock, 8: Portarlington, 9: Point Cooke, 10: Ricketts Point, 11: Martha Point, 12: Settlement Point

region of faunal change (Knox 1963, King 1972, Waters et al. 2005, Hidas et al. 2007). Fifty-one reference sites were chosen haphazardly based on their geographical dispersion along the open coast. A number of these were located within marine parks, and some were situated in remote areas accessible only by boat. Additionally, 7 'impacted' sites were chosen based on their exposure to 1 of 2 major human activities on the open coast (sewage pollution: 3 sites; heavy human visitation: 4 sites). Two of these sites were surveyed immediately adjacent to (Boags Rocks) and $0.5 \mathrm{~km}$ from (Boags Rocks East) a major shoreline sewage outfall $\left(38^{\circ} 30^{\prime} \mathrm{S}\right.$, $144^{\circ} 53^{\prime}$ E) that discharges approximately $370 \mathrm{Ml} \mathrm{d}^{-1}$ of secondarily treated effluent. Compositional changes in invertebrate and algal communities have previously been observed in the vicinity of the outfall (Brown et al. 1990, Bellgrove et al. 1997, Hindell \& Quinn 2000, Parry \& Restall 2006, Costa 2009). The third site (Pyramid Rock) was adjacent to a smaller shoreline outfall on Phillip Island that discharges $0.6 \mathrm{Ml} \mathrm{d}^{-1}$ of effluent (see Appendix 1). Four sites (Sorrento, Barwon Heads, Point Lonsdale and Point Grey; Fig. 1) were chosen based on their exposure to high levels of visitation. Previous studies conducted in this region have shown that pedestrian traffic has the potential to cause significant reduction in cover of the brown alga Hormosira banksii and in the abundance of gastropods such as Turbo undulatus, which utilise the algae as habitat (Povey \& Keough 1991). Sorrento back beach $\left(38^{\circ} 20^{\prime}\right.$ $\mathrm{S}, 144^{\circ} 43^{\prime} \mathrm{E}$ ) is one of the most accessible and popular rock platforms on the Mornington Peninsula. This site is estimated to receive over half a million visitors each year (Parks Victoria 1998, Zanon 2002), many of whom have been directly observed trampling over algal beds and collecting biota from the rock platform (Addison et al. 2008). Additionally, large numbers of European and other visitors to the platform have been recorded back to the 1870 s (J. South pers. comm. as cited by Addison et al. 2008). The other 3 heavily visited sites were chosen due to their popularity, close proximity to urban centres and high rates of recreational use. Finally, 5 sites were chosen from within 2 major Victorian Embayments, 4 in Port Phillip Bay and 1 in Western Port Bay. Sampling of the 4 site groups was randomised, most taking place between February and May 2005. Each reef was surveyed over the low tide period of $1 \mathrm{~d}$ (on tides lower than $0.4 \mathrm{~m}$ above datum).

Quantitative surveys-nested survey design. Within each site, 2 transects of $10 \mathrm{~m}$ width were placed within a $50 \mathrm{~m}$ longshore section of reef. Each transect spanned the whole length of the intertidal zone, delimited by the seaward edge of the platform at low tide and the upper limit of the high shore gastropod Austrolittorina unifasciata (Gladstone 2002). Within each transect, a $5 \times 5 \mathrm{~m}$ square was randomly placed within each of the high, mid- and low zones. The high zone was marked by the presence of littorinid snails, midshore by mussels and barnacles and the low shore by the alga Hormosira banksii and/or other similar algal species (Bennett \& Pope 1953). Five replicate quadrats measuring $50 \times 50 \mathrm{~cm}$ were randomly placed within each of these zones. All sessile and semi-sessile mol- 
luscs ( $\geq 3 \mathrm{~mm}$ ) were counted within each quadrat. All microhabitats within quadrats were recorded (e.g. crevice, emergent rock), with the constraint that quadrats were not placed in rockpools deeper than $20 \mathrm{~cm}$. In some quadrats, a small number of species (mussels and littorinids) were highly abundant (>200 ind.), in which case a subsample of 4 squares $(6.25 \times 6.25 \mathrm{~cm})$ was used to estimate their abundance.

Where sites were less than 50 m wide, the 2 transects were placed a minimum of $10 \mathrm{~m}$ apart. Animals were identified to species level using field guides, with the help of taxonomists, and with reference to museum collections. The total accumulated number of species found in all 30 quadrats was the overall value for the site.

Qualitative surveys - timed searches. In addition to quadrat sampling, 2 timed searches of 40 min duration were conducted at low tide. Each search took place within study sites of $50 \mathrm{~m}$ longshore width that were separated by at least $50 \mathrm{~m}$. Where the platforms were smaller than $50 \mathrm{~m}$, a single search was conducted. Previously plotted species accumulation curves indicated that 40 min was sufficient to encounter most species within each site (Costa 2004). All sessile and sedentary molluscs encountered during the search were included, and all microhabitats were searched, except for rockpools deeper than $20 \mathrm{~cm}$. The total number of different species from each search was combined to give an overall value for the site.

Data analysis. Taxonomic distinctness tests: A regional master list was compiled from the faunal collections of Museum Victoria and published records of the Marine Research Group of Victoria. Species were classified to all major taxonomic levels in a Linnean classification following the taxonomy of the Fauna of Australia series (Beesley et al. 1998). A constant path length $(\omega=1)$ between levels was used to calculate taxonomic distance between species pairs (Warwick \& Clarke 1995). AvTD was calculated using presence/ absence data from each site. Using each separate dataset, taxonomic distinctness was quantified using the TAXDTEST procedure in the PRIMER-E V.6 software package (Clarke \& Gorley 2006). Samples from the master list were used to generate an expected distribution of values, including a mean and $95 \%$ confidence interval. The expected distribution was represented visually as a funnel plot, showing values for different numbers of species, and the observed values were overlain on the plot. This was used to test the null hypothesis that each observed value had the same value as one predicted using the master list, rejected at the 5\% significance level (Clarke \& Warwick 2001, Warwick \& Clarke 2001, Smith \& Rule 2002), i.e. sites falling outside the $95 \%$ confidence limits were interpreted as having an AvTD value significantly lower (or higher) than expected.
AvTD tests: To compare the response of AvTD, VarTD and a range of other diversity indices, 1-way ANOVAs were conducted between (putatively) impacted and non-impacted sites. Four categories were established: heavily visited (HV), sewage (S), bay sites (B) and controls (C). Visited and sewage sites are listed in 'study sites' above. Five sites within major bays (Martha Point, Portarlington, Ricketts Point, Point Cooke and Settlement Point; Fig 1.) were included as an outgroup, as they had different environmental characteristics. As there was no evidence that assumptions of homogeneous variance were compromised, it was considered unnecessary to eliminate control sites to achieve a balanced design (Quinn \& Keough 2002); therefore, all reference sites along the coast were included in the control category (51 sites). Data from quadrat surveys and timed searches were used to calculate a number of diversity indices using the DIVERSE procedure in PRIMER-E V.6. For quadrat surveys, difference in AvTD $\left(\Delta^{+}\right)$between site categories, as well as differences in other measures of species richness including Margalef's richness $(d)$, Simpson diversity $\left(1-\lambda^{\prime}\right)$, number of species, taxonomic distinctness $\left(\Delta^{*}\right)$ and $\operatorname{VarTD}\left(\Lambda^{+}\right)$, were examined. For timed search data, AvTD, VarTD and number of species were tested. Each dataset was examined for normality and heteroscedasticity using probability plots, and variables were log transformed where necessary prior to analysis. Pearson correlation coefficients between indices were determined. ANOVAs and correlation analyses were conducted using SYSTAT V.12.0.

Environmental correlates. Gradients of temperature and exposure are known to occur along the Victorian coast (O'Hara 2001). We selected a number of environmental parameters across the coast including mean sea surface temperature, oceanographic variables (primary production, salinity, phosphate, nitrate and oxygen) wave power (a combined measure of wave height and wave period), rock hardness (measured on Moh's scale), surrounding rock area (within 1 and $10 \mathrm{~km}$ ), aspect (perpendicular angle to the shoreline), reef type (boulder reef or flat rock platform), coastal type (bay or open coast) and latitude and longitude (Costa 2009, O'Hara et al. 2010). Pearson correlation was used to examine the relationship between these environmental factors (hereafter macrofactors) and taxonomic distinctness at 60 sites along the coast (3 sewage sites were omitted). Additionally, for quadrat data, correlations between taxonomic distinctness and small-scale variables measured at 58 sites (hereafter microfactors; data were not attained at Sorrento, one of the heavily visited sites, and Fingal's Beach, one of the control sites) including rugosity (measured by trailing a fine chain along the surface of the reef under 2 quadrat sides and measuring the extended length) and percent 
cover of various microhabitat categories (algae, bare rock, sand, crevices, standing seawater and total area covered; estimated using a 50 point grid measuring 50 $\times 50 \mathrm{~cm}$ ), were assessed (an average value for each site was used). A principal component analysis (PCA) was initially conducted on the suite of standardised environmental variables, to remove any effects of correlations among original factors. Pearson correlation coefficients between AvTD values, VarTD values, number of species and each of 3 principal components for both macro- and microfactors were calculated. Pearson correlation was also used to examine the relationship between AvTD, VarTD and number of species at the 63 sites. Variables were log transformed where necessary prior to analysis to improve normality and homogeneity of variance. All analyses were conducted using SYSTAT V.12.0. Each analysis was done separately for quadrat surveys and timed searches.

\section{RESULTS}

Most of the platforms surveyed in the study had a similar distribution of microhabitats, such as emergent bare rock, boulders and crevices. A total of 87 species from 59 genera, 36 families, 16 orders and 3 classes were identified in the study and included in the master list. According to Marchant (2007), 30 families are sufficient to achieve adequate sensitivity in the AvTD index. Eight of these species were present only in bays, but as they represented only a small proportion of the regional assemblage, it was considered unnecessary to divide them or create separate master lists for bay and open coast sites.

\section{Taxonomic distinctness tests}

Funnel plots were simulated separately for quadrat surveys and timed searches (Fig. 2).

Quadrat data. Funnel plots generated using quadrat data showed that 57 sites had AvTD values close to or within the confidence limits of the predicted mean (although the majority of sites fell below this value), and 6 sites had AvTD values that fell below the $95 \%$ confidence limit (Fig. 2a). One of the latter was an impact site exposed to high levels of human visitation (Point Grey), and 1 was a bay site (Martha Point). The remaining 3 were control sites, including 1 that had almost no public access (Doughboy Island). No sites exposed to sewage pollution had lower than expected AvTD values.

Seven sites had VarTD values that were higher than expected (Fig. 2b). One was an impacted site exposed to sewage pollution (Boags Rocks), and the remainder were controls. Only 2 sites had AvTD and VarTD values that fell outside confidence limits (Port Campbell and The Crags), both of which were controls.

Timed search data. More species were generally encountered in timed searches at each site; however, more sites (9) had AvTD values below that of the 95\% confidence limit (Fig. 2c). Values at 3 of these sites also fell below the line when quadrat data were used. One of the sites was an impact site exposed to sewage pollution (Boags Rocks East), but again the remainder were control sites.

Four sites had VarTD values outside confidence limits (Fig. 2d). Three of these were higher than expected and the other fell below the predicted interval. None of these had corresponding low AvTD values, and all 4 were controls.

\section{Comparison with other indices}

A significant difference in number of species, Margalef's richness and taxonomic distinctness was found between site categories when quadrat data were used (Table 1). There was no corresponding difference in Shannon diversity, AvTD or VarTD (though AvTD was marginal, with $\mathrm{p}=0.05$ ). Tukey's tests showed a significant reduction in number of species between control and bay categories and between bay and heavily visited sites (Table 2, Fig. 3). Significant differences between control and bay sites and bay and sewage sites were also found for taxonomic distinctness, but no difference was found between site categories for Margalefs' richness. There was little difference in mean values for all indices between control and heavily visited sites (Fig. 3). Mean number of species, Margalef's richness and Simpson diversity were generally lower at sewage sites relative to controls, although these differences were not significant, and there was considerable variation among control sites. The same was true for mean values of taxonomic distinctness, AvTD and VarTD, which in this case were slightly higher relative to controls.

\section{Environmental correlates}

Macrofactors. Three principal components summarised $64.7 \%$ of the variation in environmental data (Table 3), and revealed several gradients of environmental change along the coast. The first principal component (PC) summarised $32 \%$ of the variation and was most strongly dominated by changes in wave power, salinity and phosphate levels. The second PC summarised $22 \%$, and was largely dominated by latitude and rock hardness. The third PC summarised 10.6\% 

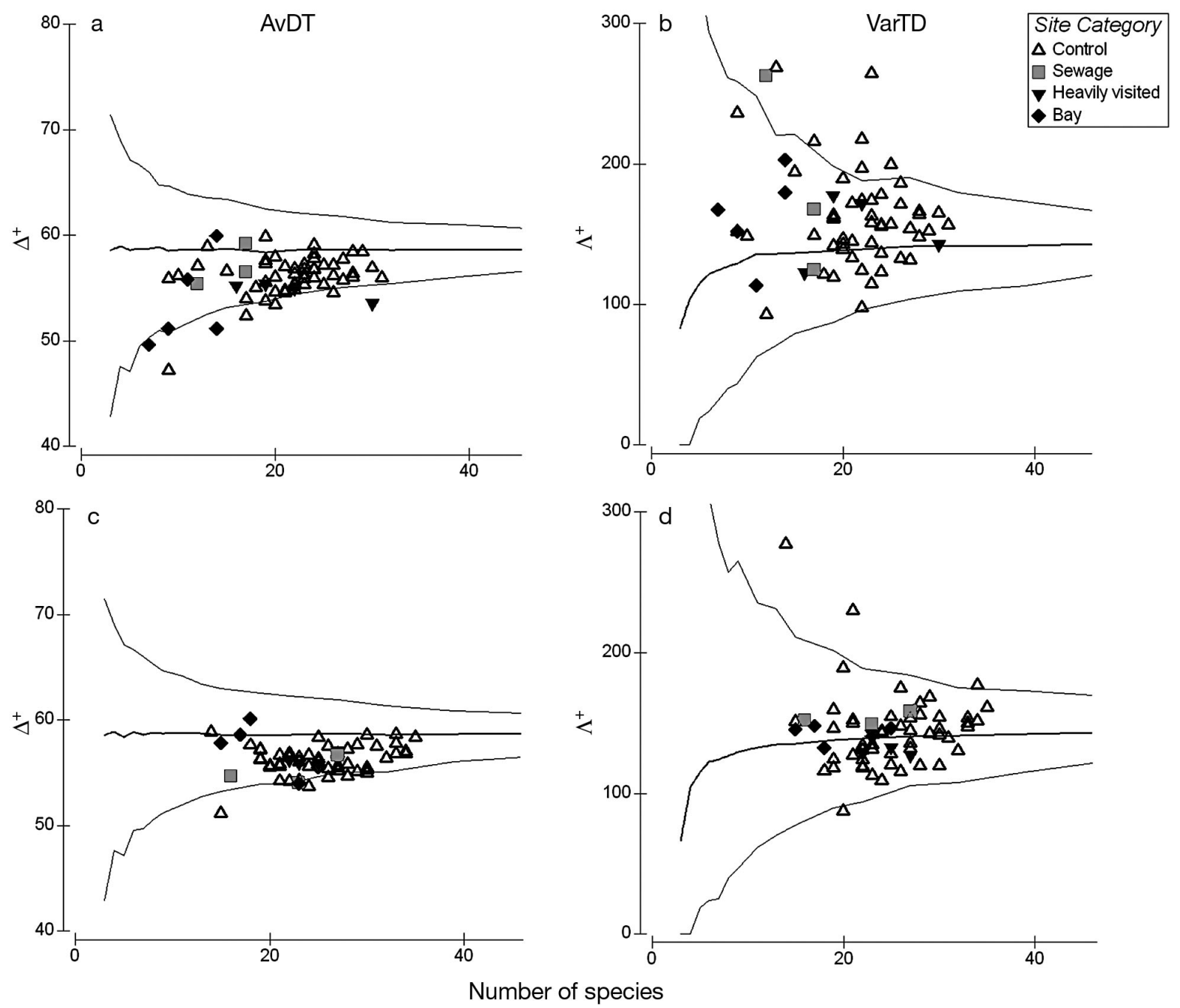

Fig. 2. Confidence funnels showing $(\mathrm{a}, \mathrm{c})$ observed average taxonomic distinctness (AvTD, $\left.\Delta^{+}\right)$and $(\mathrm{b}, \mathrm{d})$ variation in taxonomic distinctness (VarTD,$\Lambda^{+}$) values overlain on the predicted mean and its $95 \%$ confidence interval, obtained from randomly sampling values from a master list of intertidal mollusc species from across the coast of Victoria. Values were obtained from (a,b) quadrat sampling and $(\mathrm{c}, \mathrm{d})$ timed searches

Table 1. Analysis of variance table showing differences between control sites, bay sites, those exposed to sewage pollution and those exposed to high levels of human visitation, using various diversity indices. AvTD: average taxonomic distinctness, VarTD: variation in taxonomic distinctness

\begin{tabular}{|lcc|}
\hline Index & $F(3,59)$ & $\mathrm{p}$ \\
\hline Quadrats & & \\
No. species & 9.974 & $<0.0001$ \\
d, Margelef's species richness & 2.910 & 0.042 \\
1- $\lambda^{\prime}$, Simpson diversity & 2.257 & 0.063 \\
$\Delta^{*}$, Taxonomic distinctness & 4.599 & 0.006 \\
$\Delta^{+}$, AvTD & 2.765 & 0.050 \\
$\Lambda^{+}$, VarTD & 0.158 & 0.924 \\
Timed searches & & \\
No. of species & 2.468 & 0.071 \\
$\Delta^{+}$, AvTD & 1.233 & 0.306 \\
$\Lambda^{+}$, VarTD & 0.429 & 0.733 \\
\hline
\end{tabular}

and was dominated by the area of rock occurring within $1 \mathrm{~km}$ of each site.

Microfactors. Three principal components summarised $61.6 \%$ of the variation in site-specific habitat data (Table 4 ). The first PC summarised $24 \%$ of the variation and was most strongly dominated by differences in average rugosity. The second PC summarised $19 \%$, and was dominated by the mean percent cover of bare rock. The third PC summarised $18.7 \%$ and was dominated by the mean percent cover of standing water at each site.

\section{Correlations}

Macrofactors. Pearson correlation coefficients between AvTD, VarTD and each PC were low in every case regardless of whether quadrat or timed search 
Table 2. Tukey's tests showing differences between number of species at control and impact rocky intertidal platforms along the coast of Victoria. C: control sites, B: bay sites, HV: heavily visited sites, S: sewage sites, and Category: site category

\begin{tabular}{|ccccc|}
\hline Quadrats & Category 1 & Category 2 & Difference & \multicolumn{1}{c|}{$\mathrm{p}$} \\
\hline No. of species & $\mathrm{B}$ & $\mathrm{C}$ & -10.686 & $<0.0001$ \\
& $\mathrm{~B}$ & $\mathrm{HV}$ & -10.75 & 0.01 \\
& $\mathrm{~B}$ & $\mathrm{~S}$ & -4.333 & 0.631 \\
& $\mathrm{C}$ & $\mathrm{HV}$ & -0.064 & 1 \\
& $\mathrm{C}$ & $\mathrm{S}$ & 6.353 & 0.147 \\
& $\mathrm{HV}$ & $\mathrm{S}$ & 6.417 & 0.335 \\
Margalef's & $\mathrm{B}$ & $\mathrm{C}$ & -0.637 & 0.304 \\
richness & $\mathrm{B}$ & $\mathrm{HV}$ & -0.42 & 0.849 \\
& $\mathrm{~B}$ & $\mathrm{~S}$ & 0.494 & 0.818 \\
& $\mathrm{C}$ & $\mathrm{HV}$ & 0.217 & 0.949 \\
& $\mathrm{C}$ & $\mathrm{S}$ & 1.131 & 0.077 \\
Taxonomic & $\mathrm{HV}$ & $\mathrm{S}$ & 0.914 & 0.416 \\
distinctness & $\mathrm{B}$ & $\mathrm{C}$ & -0.082 & 0.003 \\
& $\mathrm{~B}$ & $\mathrm{HV}$ & -0.073 & 0.122 \\
& $\mathrm{~B}$ & $\mathrm{~S}$ & -0.098 & 0.036 \\
& $\mathrm{C}$ & $\mathrm{HV}$ & 0.009 & 0.983 \\
& $\mathrm{C}$ & $\mathrm{S}$ & -0.016 & 0.946 \\
& $\mathrm{HV}$ & $\mathrm{S}$ & -0.025 & 0.906 \\
\hline
\end{tabular}

data were used (Table 5). However, values changed, sometimes markedly, between sampling methods. Significance levels were adjusted for multiple comparisons using the Bonferroni procedure $(\alpha=0.0083)$. Significant correlations were found between number of species and PC1 (quadrat data) and VarTD and PC2 (timed search data), but neither of these variables explained more than $20 \%$ of the variance, indicating that neither AvTD nor VarTD was strongly correlated with the environmental gradients examined.

Microfactors. In the same way, Pearson correlation coefficients between AvTD, VarTD and habitat-influenced PCs were consistently low (Table 5), and not significantly different from 0 in any case $(\alpha=0.016)$. The strongest correlation was found between number of species and PC3 (-0.271).

Indices. Pearson correlation coefficients again varied between sampling methods but ranged between -0.046 and 0.39 , indicating that only a small portion of the variance $(<15 \%)$ was explained by the relationship between variables (Table 6). A significant correlation was found between number of species and AvTD (quadrat data), but this relationship accounted for only $14 \%$ of the variation.
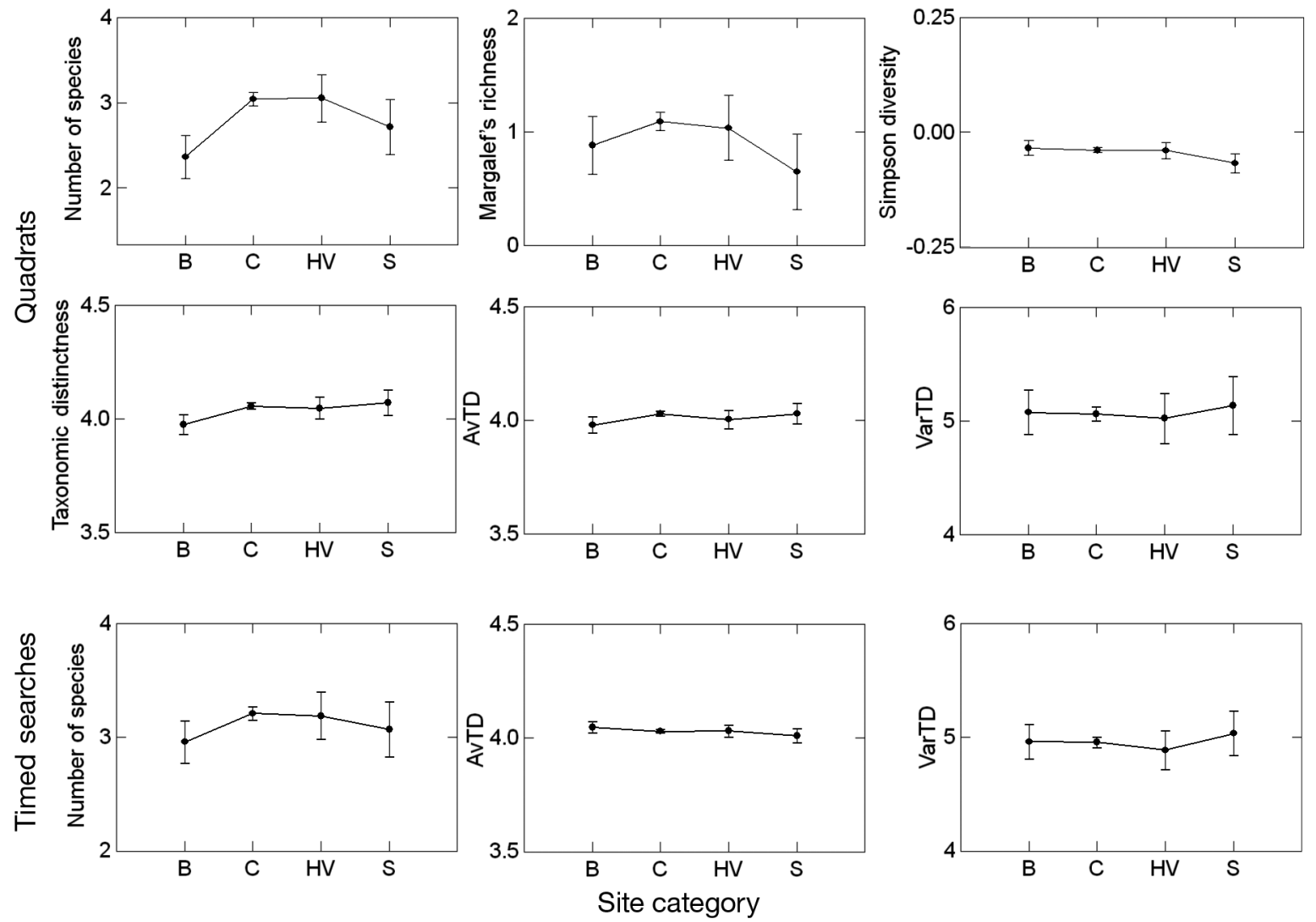

Fig. 3. Least squared means showing differences in intertidal molluscan assemblages between control sites (C), bay sites (B), those exposed to sewage (S) and those exposed to high levels of human visitation (HV), analysed using various diversity indices.

All values have been log transformed. AvTD: average taxonomic distinctness, VarTD: variation in taxonomic distinctness 
Table 3. Principal component (PC) analysis showing the contribution of a suite of environmental and physical parameters from 60 rocky intertidal platforms along the coast of Victoria

\begin{tabular}{|lrrr|}
\hline Factor & PC1 & PC2 & PC3 \\
\hline Latitude & -0.342 & 0.883 & -0.082 \\
Longitude & 0.651 & 0.688 & -0.057 \\
Aspect & -0.099 & -0.172 & -0.224 \\
Rock hardness & -0.266 & -0.702 & 0.004 \\
Reef type & 0.101 & 0.317 & -0.362 \\
Coast type & 0.685 & -0.223 & -0.202 \\
Wave power & -0.831 & -0.223 & 0.093 \\
Rock within 10 km & -0.022 & 0.394 & 0.790 \\
Rock within 1 km & 0.174 & 0.016 & 0.874 \\
Sea surface temperature & 0.585 & -0.21 & 0.061 \\
Salinity & 0.902 & 0.087 & 0.129 \\
Silica & 0.737 & -0.507 & 0.064 \\
Log productivity & 0.765 & -0.111 & -0.144 \\
Log phosphate & 0.913 & 0.067 & 0.036 \\
Log oxygen & 0.275 & -0.748 & 0.082 \\
Log nitrate & 0.335 & 0.715 & -0.116 \\
\% total variation explained & 32.032 & 22.043 & 10.599 \\
\hline
\end{tabular}

Table 4. Principal component (PC) analysis showing the contribution of a suite of site-specific habitat variables at 58 rocky intertidal platforms along the coast of Victoria

\begin{tabular}{|lrrr|}
\hline Factor & PC1 & PC2 & \multicolumn{1}{c|}{ PC3 } \\
\hline Log rugosity & 0.671 & -0.237 & -0.402 \\
Log \% cover algae & -0.501 & -0.146 & 0.530 \\
Log\% cover crevice & 0.700 & 0.138 & 0.352 \\
Log \% cover bare rock & 0.467 & 0.718 & -0.011 \\
Log\% cover sand & 0.318 & -0.409 & 0.500 \\
Log \% cover water & 0.164 & 0.262 & 0.699 \\
Log area cover & -0.375 & 0.691 & -0.055 \\
\% total variation explained & 23.987 & 18.942 & 18.693 \\
\hline
\end{tabular}

Table 5. Pearson correlation coefficients between 2 measures of taxonomic distinctness (average taxonomic distinctness, AvTD; variation in taxonomic distinctness, VarTD), number of species and 3 principal components (PCs) summarising environmental data, from 60 rocky intertidal platforms along the coast of Victoria

\begin{tabular}{|lrcrrrrr|}
\hline \multirow{2}{*}{ Principal component } & \multicolumn{2}{c}{ AvTD } & \multicolumn{3}{c}{ VarTD } & \multicolumn{2}{c}{ No. species } \\
& $\mathrm{r}$ & $\mathrm{p}$ & $\mathrm{r}$ & $\mathrm{p}$ & $\mathrm{r}$ & $\mathrm{p}$ \\
\hline Macrofactors & & & & & & & \\
Quadrats & & & & & & \\
PC1 & -0.281 & 0.029 & -0.127 & 0.332 & -0.379 & 0.003 \\
PC2 & 0.267 & 0.039 & -0.177 & 0.176 & 0.292 & 0.024 \\
PC3 & 0.043 & 0.747 & -0.161 & 0.218 & 0.308 & 0.016 \\
Timed searches & & & & & & \\
PC1 & 0.109 & 0.408 & -0.268 & 0.039 & -0.344 & 0.070 \\
PC2 & 0.034 & 0.796 & -0.455 & $<0.0005$ & 0.150 & 0.254 \\
PC3 & 0.186 & 0.154 & -0.071 & 0.59 & 0.260 & 0.045 \\
Microfactors & & & & & & \\
Quadrats & & & & & & \\
PC1 & & & & & & & \\
PC2 & 0.003 & 0.979 & 0.102 & 0.445 & 0.163 & 0.221 \\
PC3 & 0.209 & 0.116 & -0.064 & 0.634 & 0.216 & 0.103 \\
& -0.194 & 0.145 & 0.064 & 0.635 & -0.271 & 0.040 \\
\hline
\end{tabular}

Table 6. Correlation of 2 measures of taxonomic distinctness (average taxonomic distinctness, AvTD; variation in taxonomic distinctness, VarTD) and number of species at 63 rocky intertidal platforms along the coast of Victoria

\begin{tabular}{|lrrrr|}
\hline \multirow{2}{*}{ Correlation } & \multicolumn{3}{c}{ Quadrats } & \multicolumn{2}{c|}{ Timed searches } \\
& $\mathrm{r}$ & $\mathrm{p}$ & $\mathrm{r}$ & $\mathrm{p}$ \\
\hline No. species vs. AvTD & 0.381 & 0.002 & 0.128 & 0.317 \\
No. species vs. VarTD & -0.099 & 0.440 & 0.017 & 0.897 \\
\hline
\end{tabular}

\section{DISCUSSION}

In general, taxonomic distinctness indices did not consistently discriminate sites exposed to putative human impacts in this study, but in contrast to previous findings, it was not the result of strong correlation with environmental gradients. The results of the study are complex; taxonomic distinctness indices responded comparably to other diversity measures, but values varied when different sampling procedures (quadrats versus timed searches) were used. This is an important finding, although it makes interpreting the results and making general conclusions concerning the utility of the indices difficult.

Low average taxonomic distinctness was not characteristic of putatively impacted rocky intertidal molluscan assemblages along the coast of Victoria. High values were maintained across sites exposed to sewage pollution, indicating no reduction in the taxonomic breadth of the community. In the same way, values outside expectation were not consistently found at sites exposed to high levels of visitation, or bay sites with different habitat characteristics, either when they were used in the TAXDTEST procedure or treated as comparative univariate indices. VarTD values were not significantly lower or higher at impacted sites, meaning that there was no increased (or decreased) unevenness present in the taxonomic tree.

\section{Insensitivity of AvTD and VarTD}

The insensitivity of AvTD to humaninduced pressures has previously been ascribed to its association with environmental gradients (Ellingsen et al. 2005, Bhat \& Magurran 2006, Heino et al. 2007). However, environmental variation did not have a strong influence on the taxonomic distinctness of intertidal communities in Victoria. Correlations between AvTD and PCs summarising 
environmental data were generally weak, although some of the chemical data used (e.g. wave power, sea surface temperature) were extrapolated from offshore environmental data and were not taken as site-specific measurements, as our test was whether broad oceanographic features play a role. It is possible that some of these variables are modified on a local scale by physical conditions such as site aspect and topography, and that interactions occur between these factors that may influence communities (see Thrush et al. 2008). Nevertheless, changes in taxonomic distinctness were also only weakly associated with PCs derived from smallscale, site-specific microhabitat variables.

Though some of the diversity indices tested discriminated bay sites from controls, none of them discriminated impacted categories, which begs the question, were the chosen 'impact' sites really disturbed? Human activities, at least within sites exposed to sewage, have strong effects on the communities. The outfall at Boags Rocks is the largest intertidal outfall in Australia, and over the $25 \mathrm{yr}$ it has been in operation, has caused a wide range of changes in the macrofaunal community (Brown et al. 1990, Bellgrove et al. 1997, Newell et al. 1999, Hindell \& Quinn 2000, Kevekordes 2000, Kevekordes \& Clayton 2000, Parry \& Restall 2006), which is dominated by the introduced opportunistic polychaete Boccardia proboscidea, characteristic of sewage-enriched communities (Petch 1989). Notably, indices that did not incorporate measures of taxonomic relatedness (no. of species, Margalef's richness and Simpson diversity) were lower on average at sewage sites relative to controls. However, this was not reflected by either AvTD or VarTD, and neither were differences between bay and control categories.

There are a number of other possibilities why AvTD failed to discriminate putatively disturbed sites. AvTD may have been insensitive because it was calculated using presence/absence data. The impacts examined in this study may manifest as fluctuations in the abundance of species. This may be particularly true of heavily visited sites, where diffuse impacts such as trampling and harvesting often cause a decline in numbers of target organisms (Hockey \& Bosman 1986, Castilla \& Bustamante 1989, Kingsford et al. 1991, Underwood 1993, Keough \& Quinn 1998, 2000, Casu et al. 2006a,b) or restrict their distribution to small patches of refuge habitat (Addessi 1994, Lasiak \& Field 1995). However, if this were the case, it is likely that the taxonomic diversity index, which incorporates a measure of abundance, would have detected differences between control and impact categories.

AvTD values were generally low and fell below the predicted value - a finding inconsistent with previous studies that have shown that most values are evenly distributed around the mean (e.g. Marchant 2007). It is possible that poor local diversity in comparison to the regional pool is evidence of more widespread community decline. In our study, a number of rare species (occurring at a single site) were found, and may represent remnant individuals of those that have declined as a result of human activities, i.e. those targeted for consumption (e.g. Haliotis spp.) or collection (e.g. Conus spp.). However, without historical data, it is difficult to substantiate this with evidence, and there are other possibilities that may explain these distribution patterns. Many marine invertebrates are found naturally in low abundances (Underwood \& Chapman 1996, Benkendorff \& Przeslawski 2008), and many rare individuals may be subtidal vagrants, whose distribution patterns change over time and whose abundances may fluctuate in intertidal habitats.

Finally, taxonomic distinctness measures may simply be unsuitable for detecting human impacts on rocky shores. In contrast to Warwick \& Clarke's (1998) nematode data, disturbance does not result in more closely related mollusc communities. The capacity of taxonomic distinctness measures to detect human impacts relies on the assumption that disturbance will reduce the taxonomic breadth of a community by selecting closely related, stress-tolerant species, those that share a suite of similar traits and respond similarly to impacts. This may not always be the case. Species within the same genera or family may not respond the same way to disturbance. Complex community interactions, along with the frequency and magnitude of the disturbance will affect the response and sensitivity of a species or group of species (Paine et al. 1998). High taxonomic breadth may persist in a disturbed community where adaptations, derived through convergent evolution, occur in distantly related taxa (Helmus et al. 2010). Moreover, reductions in the taxonomic breadth of assemblages may not be exclusive of impacted conditions; a number of undisturbed sites in this study had naturally low AvTD values; for example, a site at Doughboy Island, considered to be a pristine environment and practically inaccessible by humans, had the lowest AvTD value of all sites surveyed.

Natural habitat variations could cause marked changes in taxonomic distinctness between communities if they are associated with organisms that differ at high taxonomic levels (e.g. Bevilacqua et al. 2009). While no significant correlation with microhabitat variables was found in this study, the combination of low AvTD/high VarTD values at many of the sites suggests unevenness in the distribution of distantly related taxa, which may be attributable to small-scale habitat variation. Indeed, in this study, the ratio of higher to lower level diversity appears to be greater than what has previously been examined in other habitats. The master list in this study was comprised of 87 species distrib- 
uted among 16 orders. In contrast, the nematode list of Warwick \& Clarke (1998) consisted of 395 species distributed among 4 orders, and the molluscan list of Terlizzi et al. (2005) consisted of 151 species from 19 orders. In a study describing the effects of disturbance on insect communities from freshwater rivers, Marchant (2007) proposed that lack of sensitivity in AvTD was a result of too little variation at mid-high taxonomic levels. The results of this study suggest the converse; within intertidal mollusc communities, diversity at lower levels is insufficient for taxonomic distinctness to be substantially affected or lowered by human impacts. Molluscs form the largest component of intertidal rocky shore fauna and were the only taxonomic group suitable for use in this study, but while they may be sufficiently representative of biodiversity for conservation planning, they may not be useful for community monitoring purposes.

\section{Taxonomic distinctness versus other diversity indices}

Indices of taxonomic distinctness have previously been found to be more sensitive to human disturbance than other diversity indices (Warwick \& Clarke 1995, Terlizzi et al. 2005, Roberts \& Connell 2008), but this was not supported in our study. Although none of the indices tested using 1-way ANOVAs discriminated significant differences between control and impacted groups, the behaviour of taxonomic distinctness indices in response to enrichment by sewage suggests that they are in fact less sensitive than conventional indices. Measures incorporating a measure of taxonomic relatedness showed a mean increase at sites exposed to sewage pollution, where number of species, Margalef's richness and Simpson diversity all showed a decline.

Nevertheless, in contrast to previous studies (Heino 2005), AvTD was not strongly correlated with other diversity indices, demonstrating that although it is not necessarily a more sensitive indicator of anthropogenic activity, it is not redundant as a biodiversity index. Lack of correlation between AvTD, VarTD and number of species suggests that increasing number of species at a site does not denote either increased or decreased taxonomic breadth in the assemblage; there is no apparent pattern in the way both congeneric species and more distantly related taxa appear in these assemblages across the coast.

\section{Sampling procedures}

Generally, when timed searches were used, more species were found, AvTD values were higher, VarTD values were lower and there was less variability in values between sites than when quadrats were used. This result is surprising and contradicts what was predicted by the funnel plots. Predicted mean values generated from sampling the master list remained constant, even with increased numbers of species. This indicates that the increase in AvTD is not a result of increased sampling effort, but rather, that a procedural difference affects the number and type of species found. Species from unrelated taxa can be associated with different microhabitat types, e.g. emergent shores and crevices. It is likely that more species were found in timed searches than quadrats because more microhabitats, such as reef fringes, refuge habitats and crevices, were searched. This increased the likelihood of finding vagrant, subtidal, rare, and patchily distributed species that were more taxonomically distinct from the rest of the common assemblage.

Quadrat samples generally had a lower taxonomic breadth with more variability amongst sites. The high level of variation in VarTD values indicates that species from higher taxa appear sporadically in these assemblages. Differences in the proportion of microhabitats sampled at each site may explain the variation in taxonomic distinctness values. Quadrats were not stratified according to microhabitat because, theoretically, AvTD and VarTD are calculated using presence/ absence data, meaning that only 1 example of each microhabitat must be sampled at each site to capture its associated fauna (which was usually the case). Nevertheless, variability was lower when timed searches were used (and a wider range of microhabitats was searched), which implies that stratification of quadrats according to habitat may be necessary, and more replicates may be required to reduce variation between sites and ensure the assemblage is adequately represented.

Based on the findings of this study, it is problematic to determine which sampling method is more appropriate for quantifying human impacts. Different techniques may be more suitable for assessing different impact types; for example, quadrats stratified across open platform habitats may be more sensitive to detecting the effects of heavy visitation, such as trampling and harvesting, than timed searches, because the spatial scale of both trampling and harvesting is smaller than that of pollution or sewage enrichment. Timed searches give a more comprehensive representation of which species occupy a site, but may be more appropriate for quantifying impacts that result in the complete loss of species. It is evident, however, that systematic sampling bias can influence taxonomic distinctness, which should be taken into consideration when data are to be collated from a number of sources. 


\section{CONCLUSIONS}

There have been varied results in the literature on the usefulness of measures of taxonomic distinctness for assessing human impacts, or determining the ecological 'health' of a community (Salas et al. 2006). In our study, putatively impacted sites maintained a high degree of taxonomic 'resilience', and many control sites exhibited low values of taxonomic distinctness, meaning that these indices were not useful for discriminating rocky shore communities exposed to sewage or heavy human visitation. Nevertheless, our results revealed interesting patterns concerning the use of different sampling procedures; we suggest further investigation of the effects of procedural differences on the use of these indices in other habitats.

Acknowledgements. The project was funded by a Special Postgraduate Studentship from Melbourne University and Museum Victoria, an Albert Shimmins Postgraduate write-up award from the University of Melbourne, as well as various grants from the National Heritage Trust, Parks Victoria and the Victorian Environmental Protection Authority. We thank R. Marchant (Museum Victoria) for statistical advice, the late C. Hendrick (Marine Research Group of Victoria) for assistance with identifying animals, and Parks Victoria for facilitating access to remote sites.

\section{LITERATURE CITED}

Addessi L (1994) Human disturbance and long-term changes on a rocky intertidal community. Ecol Appl 4:786-797

Addison PA, Koss RS, O'Hara TD (2008) Recreational use of a rocky intertidal reef in Victoria: implications for ecological research and management. Australas J Environ Manag 15:169-179

Beesley PL, Ross GJB, Wells A (eds) (1998) Mollusca: the southern synthesis. CSIRO Publishing, Melbourne

Bellgrove A, Clayton MN, Quinn GP (1997) Effects of secondarily treated sewage effluent on intertidal macroalgal recruitment processes. Mar Freshw Res 48:137-146

Benkendorff K, Davis AR (2002) Identifying hotspots of molluscan species richness on rocky intertidal reefs. Biodivers Conserv 11:1959-1973

Benkendorff K, Przeslawski R (2008) Multiple measures are necessary to assess rarity in macro-molluscs: a case study from southeastern Australia. Biodivers Conserv 17: 2455-2478

Bennett I, Pope EC (1953) Intertidal zonation of the exposed rocky shores of Victoria, together with a rearrangement of the biogeographical provinces of temperate Australian shores. Aust J Mar Freshw Res 4:105-158

Bevilacqua S, Fraschetti S, Terlizzi A, Boero F (2009) The use of taxonomic distinctness indices in assessing patterns of biodiversity in modular organisms. Mar Ecol 30:151-163

Bhat A, Magurran AE (2006) Taxonomic distinctness in a linear system: a test using a tropical freshwater fish assemblage. Ecography 29:104-110

Blanchard D, Bourget E (1999) Scales of coastal heterogeneity: influence on intertidal community structure. Mar Ecol Prog Ser 179:163-173

Brown VB, Davies SA, Synnot RN (1990) Long-term monitor- ing of the effects of treated sewage effluent on the intertidal macroalgal community near Cape Schanck, Victoria, Australia. Bot Mar 33:85-98

> Buckland ST, Magurran AE, Green RE, Fewster RM (2005) Monitoring change in biodiversity through composite indices. Philos Trans R Soc B Biol Sci 360:243-254

Castilla JC, Bustamante RH (1989) Human exclusion from rocky intertidal of Las Cruces, central Chile: effects on Durvillaea antartica (Phaeophyta, Durvilleales). Mar Ecol Prog Ser 50:203-214

> Casu D, Ceccherelli G, Castelli A (2006a) Immediate effects of experimental human trampling on mid-upper intertidal benthic invertebrates at the Asinara Island MPA (NW Mediterranean). Hydrobiologia 555:271-279

Casu D, Ceccherelli G, Curini-Galletti M, Castelli A (2006b) Short-term effects of experimental trampling on polychaetes of a rocky intertidal substratum (Asinara Island MPA, NW Mediterranean). Sci Mar 70:179-186

Clarke KR (1993) Nonparametric multivariate analyses of changes in community structure. Aust J Ecol 18:117-143

Clarke KR, Gorley RN (2006) PRIMER 6 user manual/tutorial, Natural Environment Research Council and Plymouth Marine Laboratory (PRIMER-E Ltd), Plymouth

Clarke KR, Warwick RM (1998) A taxonomic distinctness index and its statistical properties. J Appl Ecol 35:523-531

Clarke KR, Warwick RM (1999) The taxonomic distinctness measure of biodiversity: weighting of step lengths between hierarchical levels. Mar Ecol Prog Ser 184:21-29

> Clarke KR, Warwick RM (2001) A further biodiversity index applicable to species lists: variation in taxonomic distinctness. Mar Ecol Prog Ser 216:265-278

Costa TL (2004) An experimental investigation into the biogeography of species richness and distribution patterns along the southeast coast of Australia. Honours thesis, University of Wollongong

Costa TL (2009) Detecting anthropogenic disturbance in the rocky intertidal: a study of rocky shores in Victoria. PhD thesis, University of Melbourne

Dufrene M, Legendre P (1997) Species assemblages and indicator species: the need for a flexible asymmetrical approach. Ecol Monogr 67:345-366

Ellingsen KE, Clarke KR, Somerfield PJ, Warwick RM (2005) Taxonomic distinctness as a measure of diversity applied over a large scale: the benthos of the Norwegian continental shelf. J Anim Ecol 74:1069-1079

- Fairweather PG (1990) Sewage and the biota on seashores: assessment of impact in relation to natural variability. Environ Monit Assess 14:197-210

Fleishman E, Noss RF, Noon BR (2006) Utility and limitations of species richness metrics for conservation planning. Ecol Indic 6:543-553

Gladstone W (2002) The potential value of indicator groups in the selection of marine reserves. Biol Conserv 104: $211-220$

Hall SJ, Greenstreet SP (1998) Taxonomic distinctness and diversity measures: responses in marine fish communities. Mar Ecol Prog Ser 166:227-229

Harper JL, Hawksworth DL (1994) Biodiversity - measurement and estimation: preface. Philos Trans R Soc Lond B Biol Sci 345:5-12

Hawkins SJ, Hartnoll RG, Williams GA, Azzopardi PJ, Burrows MT, Ellard FM (1986) Effectiveness of sampling strategies for intertidal monitoring. Water Sci Technol 18: $63-72$

Heino J (2005) Functional biodiversity of macroinvertebrate assemblages along major ecological gradients of boreal headwater streams. Freshw Biol 50:1578-1587 
Heino J, Mykra H, Hamalainen H, Aroviita J, Muotka T (2007) Responses of taxonomic distinctness and species diversity indices to anthropogenic impacts and natural environmental gradients in stream macroinvertebrates. Freshw Biol 52:1846-1861

Helmus MR, Keller W, Paterson MJ, Yan ND, Cannon CH, Rusak JA (2010) Communities contain closely related species during ecosystem disturbance. Ecol Lett 13:162-174

$>$ Hewitt JE, Anderson MJ, Thrush SF (2005) Assessing and monitoring ecological community health in marine systems. Ecol Appl 15:942-953

Hidas EZ, Costa TL, Ayre DJ, Minchinton TE (2007) Is the species composition of rocky intertidal invertebrates across a biogeographic barrier in southeastern Australia related to their potential for dispersal? Mar Freshw Res 58:835-842

Hindell JS, Quinn GP (2000) Effects of sewage effluent on the population structure of Brachidontes rostratus (Mytilidae) on a temperate intertidal rocky shore. Mar Freshw Res 51: 543-551

> Hockey PAR, Bosman AL (1986) Man as an intertidal predator in Transkei: disturbance, community convergence and management of a natural food resource. Oikos 46:3-14

Keough MJ, Quinn GP (1991) Causality and the choice of measurements for detecting human impacts in marine environments. Aust J Mar Freshw Res 42:539-554

Keough MJ, Quinn GP (1998) Effects of periodic disturbances from trampling on rocky intertidal algal beds. Ecol Appl 8: 141-161

Keough MJ, Quinn GP (2000) Legislative vs. practical protection of an intertidal shoreline in southeastern Australia. Ecol Appl 10:871-881

Kevekordes K (2000) The effects of secondary-treated sewage effluent and reduced salinity on specific events in the early life stages of Hormosira banskii (Phaeophyceae). Eur J Phycol 35:365-371

Kevekordes K, Clayton MN (2000) Development of Hormosira banksii (Phaeophyceae) embryos in selected components of secondarily-treated sewage effluent. J Phycol 36:25-32

King RJ (1972) The distribution and zonation of intertidal organisms of rocky coasts in southeastern Australia. PhD thesis, University of Melbourne

Kingsford MJ, Underwood AJ, Kennelly SJ (1991) Humans as predators on rocky reefs in New South Wales, Australia. Mar Ecol Prog Ser 72:1-14

Knox GA (1963) The biogeography and intertidal ecology of the Australasian coasts. Oceanogr Mar Biol Annu Rev 1: 341-404

> Lasiak TA, Field JG (1995) Community-level attributes of exploited and non-exploited rocky infratidal macrofaunal assemblages in Transkei. J Exp Mar Biol Ecol 185:33-53

Magurran AE (2004) Measuring biological diversity, Blackwell, Oxford

Marchant R (2007) The use of taxonomic distinctness to assess environmental disturbance of insect communities from running water. Freshw Biol 52:1634-1645

Newell B, Molloy R, Fox D (1999) Environmental impact assessment and review of effluent disposal options for Eastern Treatment Plant - final report. CSIRO Environmental Projects Office, Canberra

O'Hara TD (2001) Consistency of faunal and floral assemblages within temperate subtidal rocky reef habitats. Mar Freshw Res 52:853-863

O'Hara TD, Addison PFE, Gazzard R, Costa TL, Pocklington JB (2010) A rapid bioassessment model for intertidal rocky shores. Aquat Conserv: Mar Freshw Ecosyst 20:452-463

Paine RT, Tegner MJ, Johnson EA (1998) Compounded perturbations yield ecological surprises. Ecosystems 1:535-545

Parks Victoria (1998) Mornington Peninsula National Park and Arthur Seat State Park Management Plan. Parks Victoria, Melbourne

Parry GD, Restall JE (2006) Effect of Eastern (sewage) Treatment Plant effluent discharge at Boags Rocks on adjacent rocky reefs. Report no. 18, Primary Industries Research Victoria, Queenscliff

Petch DA (1989) Variation in the spionid polychaete Boccardia proboscidea. PhD thesis, University of Melbourne

Povey A, Keough MJ (1991) Effects of trampling on plant and animal populations on rocky shores. Oikos 61:355-368

Quinn GP, Keough MJ (2002) Experimental design and data analysis for biologists. Cambridge University Press, Cambridge

Roberts BK, Connell SD (2008) Detecting benthic responses to human-induced change: effectiveness of alternate taxonomic classification and indices. Mar Ecol Prog Ser 358: 75-84

Rogers SI, Clarke KR, Reynolds JD (1999) The taxonomic distinctness of coastal bottom-dwelling fish communities of the north-east Atlantic. J Anim Ecol 68:769-782

Salas F, Marcos C, Neto JM, Patricio J, Perez-Ruzafa A, Marques JC (2006) User-friendly guide for using benthic ecological indicators in coastal and marine quality assessment. Ocean Coast Manag 49:308-331

Smith SDA (2005) Rapid assessment of invertebrate biodiversity on rocky shores: Where there's a whelk there's a way. Biodivers Conserv 14:3565-3576

Smith SDA (2008) Interpreting molluscan death assemblages on rocky shores: Are they representative of the regional fauna? J Exp Mar Biol Ecol 366:151-159

Smith SDA, Rule MJ (2002) Artificial substrata in a shallow sublittoral habitat: Do they adequately represent natural habitats or the local species pool? J Exp Mar Biol Ecol 277 : 25-41

Smith SDA, Simpson RD (2002) Spatial variation in the community structure of intertidal habitats at Macquarie Island (sub-Antarctic). Antarct Sci 14:374-384

Somerfield PJ, Olsgard F, Carr MR (1997) A further examination of two new taxonomic distinctness measures. Mar Ecol Prog Ser 154:303-306

> Terlizzi A, Scuderi D, Fraschetti S, Anderson MJ (2005) Quantifying effects of pollution on biodiversity: a case study of highly diverse molluscan assemblages in the Mediterranean. Mar Biol 148:293-305

> Thrush SF, Hewitt JE, Hickey CW, Kelly S (2008) Multiple stressor effects identified from species abundance distributions: interactions between urban contaminants and species habitat relationships. J Exp Mar Biol Ecol 366: $160-168$

- Underwood AJ (1993) Exploitation of species on the rocky coast of New South Wales (Australia) and options for its management. Ocean Coast Manag 20:41-62

Underwood AJ, Chapman MG (1996) Scales of spatial patterns of distribution of intertidal invertebrates. Oecologia 107:212-224

> Warwick RM, Clarke KR (1995) New 'biodiversity' measures reveal a decrease in taxonomic distinctness with increasing stress. Mar Ecol Prog Ser 129:301-305

- Warwick RM, Clarke KR (1998) Taxonomic distinctness and environmental assessment. J Appl Ecol 35:532-543

Warwick RM, Clarke KR (2001) Practical measures of marine biodiversity based on relatedness of species. Oceanogr Mar Biol Annu Rev 39:207-231

Waters JM, O'Laughlin PM, Spencer HG (2005) Phylogeographical disjunction in abundant high-dispersal littoral gastropods. Mol Ecol 14:2789-2802

Zanon D (2002) Mornington Peninsula National Park visitor vehicle monitoring project. Parks Victoria, Melbourne 
Appendix 1. Constituents and their mean monthly concentrations $\left(\mathrm{mg} \mathrm{l}^{-1}\right)$ of the effluent discharged from the shoreline outfalls at Boags Rocks and Pyramid Rock, central Victoria. NA: not analysed. Sources: Boags Rocks (Newell et al. 1999), Pyramid Rock (Westernport Water pers. comm)

\begin{tabular}{|lcc|}
\hline Constituent & $\begin{array}{c}\text { Boags Rocks } \\
(1995 / 96)\end{array}$ & $\begin{array}{c}\text { Pyramid Rock } \\
(1994 / 95)\end{array}$ \\
\hline Ammonia & 25.7 & 2.74 \\
Organic nitrogen & 33.7 & 22.52 \\
Total phosphorus & 6 & 8.475 \\
Cadmium & $<0.001$ & NA \\
Chromium & $<0.01$ & NA \\
Copper & 0.02 & NA \\
Lead & $<0.01$ & NA \\
Mercury & $<0.0002$ & NA \\
Total residual chlorine & $<0.1$ & 0.128 \\
Dissolved oxygen & 7.9 & 4.89 \\
Suspended solids & 17.5 & 8.05 \\
\hline
\end{tabular}

Editorial responsibility: Laura Airoldi, Ravenna, Italy
Submitted: November 10, 2009; Accepted: June 24, 2010 Proofs received from author(s): August 14, 2010 